Revista Eletrônica do Mestrado

Profissional em Administração da UnP

\title{
edunp
}

V. 11, N. 2,2019

ISSN 1984-4204

https://repositorio.unp.br/index.php/raunp

https://doi.org/10.21714/raunp.v11i2.2081

\section{Análise da propensão à lealdade, seus antecedentes e consequências em dois grupos culturais distintos}

\section{Analysis of the propensity to loyalty, its background and consequences in two distinct cultural groups}

\author{
Tatiana Piccin ${ }^{\mathrm{a}}$, Fernanda Lazzarib ${ }^{\mathrm{b}}$, Roberto Birch Gonçalves ${ }^{\mathrm{c}}$, Fábio Verruck ${ }^{\mathrm{d}}$ \\ a Bacharel em Comércio Internacional. Profissional de mercado na área de exportação. Universidade de Caxias do Sul. piccintati@ \\ gmail.com \\ ${ }^{b}$ Doutora em Administração. Professora do Centro de Ciências Sociais e do corpo docente permanente do Programa de Pós-Gradu- \\ ação em Administração da Universidade de Caxias do Sul. flazzar3@ucs.br \\ ' Doutor em Administração. Prof. Mestrado profissional em Biotecnologia e Gestão Vitivinícola (PPGVIT). Universidade de Caxias \\ do Sul.rbgoncal@ucs.br \\ d Doutor em Administração. Coordenador de Curso de Graduação. Universidade de Caxias do Sul. fverruck@ucs.br
}

\section{Resumo}

O presente estudo analisa a propensão à lealdade, seus antecedentes e consequências em dois grupos culturais distintos. Para tal foi aplicada uma pesquisa quantitativa de caráter descritivo, que foi operacionalizada por meio de um experimento que mediu propensão de lealdade dos indivíduos, satisfação, confiança, marketing boca a boca e resistência aos esforços da concorrência, no contexto de voos comerciais internacionais. A escolha dos países foi baseada na classificação de países proposta por Hofstede, Hofstede e Minkov (2010), sobre a dimensão cultural individualismo. Para tanto, foi escolhido um país com perfil individualista (Estados Unidos) e um país com perfil coletivista (Brasil). Para análise dos resultados utilizou-se o programa estatístico SPSS e foram realizadas análises descritivas e de variância. Foram obtidos 185 casos válidos distribuídos entre os dois países (99 norte-americanos e 86 brasileiros). Os resultados apontaram a maior propensão à lealdade dos brasileiros em comparação aos norte-americanos. No entanto, os norte-americanos apresentaram médias mais altas com relação à satisfação, confiança, marketing boca a boca e resistência aos esforços da concorrência.

Palavras-chave: Lealdade; Antecedentes da lealdade; Consequências da lealdade; Individualismo; Coletivismo.

\begin{abstract}
The present study analyzes the propensity for loyalty, its antecedents and consequences in two distinct cultural groups. For this purpose, a descriptive quantitative research was applied and it was operationalized through an experiment that measured individuals' propensity for loyalty, satisfaction, trust, word of mouth, and resistance to competition efforts in the context of international commercial flights. The countries were chosen based on the classification proposed by Hofstede, Hofstede and Minkov (2010), on the cultural dimension individualism. Thus, it was chosen a country with individualistic characteristics (United States) and a country with collectivist characteristics (Brazil). The analysis of the results was through the SPSS statistical program and descriptive and variance analyzes were performed. There were 185 valid cases distributed between the two countries (99 North Americans and 86 Brazilians). The results showed the greater propensity to loyalty of the Brazilians in comparison to the North Americans. However, Americans showed higher averages for satisfaction, trust, word of mouth, and resistance to competition efforts.
\end{abstract}

Keywords: Loyalty; Antecedents of loyalty; Consequences of loyalty; Individualism; Collectivism. 


\section{Introdução}

As estratégias de marketing, construção de produto e conexão com o consumidor, tomadas pelas empresas podem ser interpretadas diferentemente entre as nações (Hur, Kang \& Kim, 2015), uma vez que a motivação de um indivíduo para consumir não é meramente pelos atributos do produto, mas também pelo entendimento e significado que a cultura dá ao produto e ao ato da compra (Ijewere \& Odia, 2012). Logo, as características culturais de um país, incluindo a sua orientação cultural, fazem parte do conjunto de elementos que influencia o comportamento dos consumidores frente às estratégias de marketing (Frank, Enkawa \& Schavaneveldt, 2015).

Ter uma marca sólida no mercado pode influenciar o consumidor a reduzir suas opções de escolha, em determinada decisão de compra, de forma a comprar um produto de uma marca que lhe ofereça menos riscos e lhe transmita confiança (Matzler, Grabner-Krauter \& Bidmon, 2008).

Além da confiança, a satisfação, afeto (Matzler et al., 2008), experiência (Warlop, Ratneshwat \& Van Osselaer, 2005) e identificação com a marca (Schau, Muñiz \& Arnould, 2009) são fatores que, quando bem gerenciados, são importantes para a construção de uma relação de longa duração com o consumidor.

Logo, uma empresa que adota a estratégia de instigar a lealdade dos seus consumidores constrói uma barreira substancial a concorrentes, aumenta suas habilidades de responder às ameaças dos consumidores, aumenta vendas e estrutura uma base de consumidores menos sensíveis aos esforços de marketing da concorrência (Delgado-Ballester \& Munuera-Alemán, 1999). A pesquisa de Hur et al. (2015) aponta que a relação com o consumidor e os esforços de marketing podem ter diferentes reações e resultados dependendo da orientação cultural do consumidor.

Sobre a lealdade do consumidor, há duas formas de analisar a lealdade atitudinal. A primeira baseiase em uma categoria de produto ou marca específicos e a segunda apoia-se na propensão de o indivíduo ser leal independente da marca (Bennett \& Rundle-Thiele, 2002; LI, 2010). Relacionado a isso, tem-se as consequências de um consumidor leal: ações de suporte a marca e marketing boca a boca, conforme aponta Kuenzel e Halliday (2008).

Nesse sentido, uma das dimensões culturais propostas por Hofstede, Hofstede, e Minkov (2010) é o individualismo (vs. coletivismo). Essa dimensão trata da forma diferente com que as pessoas vivem o "eu" entre as nações. Assim, têm-se sociedades em que os interesses do indivíduo prevalecem sobre os interesses do grupo (individualistas) e aquelas em que os interesses do grupo prevalecem aos interesses do indivíduo, classificadas como coletivistas (Hofstede et al., 2010).

Frente a isso, pretende-se com este estudo analisar a propensão à lealdade, seus antecedentes e consequências em dois grupos culturais distintos. Para tanto, inicialmente, fez-se a seleção dos países parte da pesquisa, com base na dimensão cultural escolhida (individualismo vs. coletivismo). Na sequência, verificouse a propensão de lealdade, a satisfação e a confiança dos consumidores dos países parte da pesquisa. Por fim, foram mensuradas a predisposição dos consumidores pesquisados a praticar marketing boca a boca e sua resistência à persuasão da concorrência.

O estudo mostra-se relevante na medida em que, frente ao cenário do aumento exponencial de oferta de produtos no mercado e surgimento de novas marcas, os esforços de marketing das empresas para conseguir fidelizar os seus consumidores se tornam mais complexos e necessitam de mais especificidade para atingir não somente a satisfação do consumidor através de características intrínsecas a marca, mas também outros atributos abstratos (Delgado-Ballester \& Munuera-Alemán, 1999). E tratando-se de consumo, Solomon (2016) afirma 
que não é possível compreende-lo sem que se considere seu contexto cultural. Além disso, deve-se acrescentar às análises o conhecimento da propensão à lealdade do consumidor em questão, uma vez que sem esse alicerce as estratégias de marketing podem estar sendo alocadas de forma ineficaz (LI, 2010).

Por fim, Hur et al. (2015) indicam a necessidade de estudos que investiguem a lealdade em âmbitos internacionais, já que a relação da cultura no processo de decisão do consumidor não tem sido suficientemente explorada, apesar da importância da adaptação, entre as culturas, das estratégias de marketing em um mercado global (Frank et al., 2015).

\section{Referencial teórico}

\section{1 individualismo e a relação com o comportamento do consumidor}

Han e Shavitt (1994) afirmam que dentre as dimensões estudadas por Geert Hofstede, individualismo vs. coletivismo é a principal quando se trata de comparação cultural. Tal comparação pode ser analisada olhando para o indivíduo e para a sociedade como um todo e, dependendo da escolha, a forma como a dimensão é estudada deve se adaptar.

Além de Hofstede et al. (2010), Frank et al. (2015) também defendem com seu estudo que o individualismo cultural é mais influente no comportamento do consumidor do que o individualismo pessoal. O estudo também aponta que as médias obtidas em subculturas (estados, municípios) são altamente similares às obtidas para a cultura do país. Portanto, para este estudo o objeto de pesquisa é a sociedade como um todo; o individualismo vs. coletivismo analisados em âmbito nacional.

Yoo (2009) defende a interdependência de membros de culturas coletivistas e frisa que eles não tomarão uma decisão sobre algum assunto até ouvir opiniões de terceiros e estarão mais vulneráveis à influência dos outros a ponto de desistir da ideia original. Sobre os individualistas, o autor afirma que a competição é desejável entre os membros. Como resultado, indivíduos de cultura individualista não se importarão em trocar de marca se o objetivo for buscar a sua maior satisfação.

Segundo Ijewere e Odia (2012), a cultura afeta os motivos, compreensão de marca, atitude e intenção de usar um produto ou serviço, ou seja, a cultura cria significado para produtos. Análogo a isso, um estudo comparou 15 países europeus e encontrou muitas correlações entre comportamento do consumidor e individualismo (Hofstede et al., 2010).

A relação do individualismo vs. coletivismo com o comportamento do consumidor também é encontrada no estudo de Frank et al. (2015). Foram analisadas algumas diferenças da dimensão cultural como uma orientação nacional e pessoal; e a influência desta na intenção de recompra em seis países e dez segmentos distintos do mercado. Entre os resultados está a confirmação que uma orientação individualista modera fortemente em serviços a satisfação do consumidor, ou seja, consumidores de países individualistas quando altamente satisfeitos com um serviço estão mais propensos a recomprar.

Por fim, o estudo sustenta a ideia que além do individualismo vs. coletivismo ser a dimensão que mais explica as diferenças internacionais na psicologia, essa afirmação pode ser estendida para o marketing, mais especificamente no comportamento de recompra. Frente a isso, as estratégias de retenção de clientes devem ser aprimoradas considerando as diferenças culturais, focando no país como um todo e não em grupos de subculturas, uma vez que a diferença é pequena e a facilidade na coleta é maior. 


\subsection{Lealdade: antecedentes e consequências}

Mellens, Dekimpe e Steenkamp (1996) comentam sobre duas formas de mensurar a lealdade: lealdade orientada pela marca e lealdade orientada pelo indivíduo. A diferença entre as duas é que a primeira se baseia em uma ou um grupo de marcas específico sob análise, já a segunda considera lealdade como sendo ou não uma característica do consumidor.

Ainda sob a visão dos mesmos autores, é sustentada a ideia de que a fidelidade, inicialmente, não é resultado da avaliação de um grupo específico de marcas, mas é causada pela personalidade do consumidor ou pela forma com que toma decisões. Assim, a lealdade à marca é expressa por uma bateria de declarações sobre o comportamento geral individual, em vez de declarações sobre marcas específicas. Portanto, lealdade atitudinal orientada pelo indivíduo, na visão de ser uma característica geral do indivíduo, é tratada como sendo intrínseca à personalidade. Uma vez que a cultura é personalidade de uma sociedade (Solomon, 2016) vê-se a oportunidade de estudar a propensão de uma sociedade a ser leal dentro do âmbito de consumo.

Assim, Dick e Basu (1994) explicam que o consumidor que possui atitude positiva e também comportamento de recompra, é aquele mais propenso a ser leal a uma marca. Este cenário implica em fenômenos que são abordados pelos estudos de Kuenzel e Halliday (2008), Evanschitzky et al. (2012), Albert, Merunka e Valette-Florence (2013), Caruana (2004) e Triantafillidou e Siomkos (2014), e estão indicados na Fig. 1:

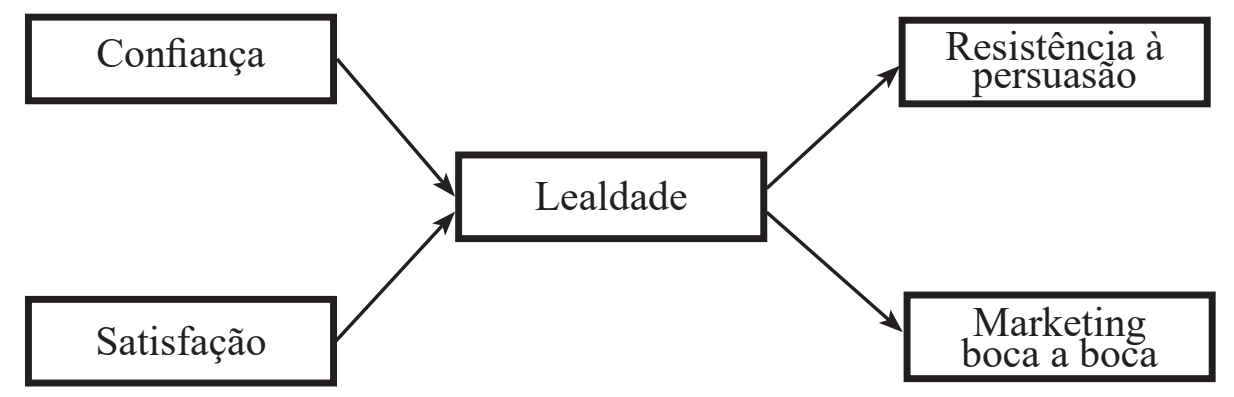

Fig. 1: Modelo de antecedentes e consequências da Lealdade

Fonte: Baseado em Delgado-Ballester e Munuera-Alemán (1999); Dick e Basu (1994).

A relação entre satisfação e lealdade é corroborada por Delgado-Ballester e Munuera-Alemán (1999) e também por Evanschitzky et al. (2012), que afirmam que a satisfação exerce efeito positivo significante à lealdade. Bloemer e Kasper (1995) destacam que, além de o consumidor se sentir satisfeito, é muito importante que tal satisfação seja manifestada de forma explícita, para que possa conduzir a um estágio de comprometimento com a marca, elemento que compõe o conceito de fidelidade.

Contudo, Delgado-Ballester e Munuera-Alemán(1999) confirmam com seu estudo que entre a satisfação e a lealdade, atua a confiança do consumidor, afetando diretamente o comprometimento do consumidor, principalmente em situações de alto envolvimento. Confiança a uma marca é o sentimento de segurança de que as expectativas de consumo serão atendidas (Delgado-Ballester \& Munuera-Alemán, 1999). A sua relação como antecedente de lealdade é abordada e confirmada nos estudos de Evanschitzky et al. (2012), Thompson, Newman e Liu (2014) e Hur et al. (2015).

\subsection{Lealdade e a sua relação com características culturais}


A retenção de consumidores pode ser intensificada através do ajuste nas estratégias de marketing para diferentes culturas. No entanto, trata-se de cultura em nível nacional, uma vez que a coleta dos dados é simples, efetiva e os resultados são altamente similares quando comparados a cultura de subgrupos (Frank et al., 2015).

Nesse sentido, o estudo de Morgeson et al. (2011) buscou possíveis variações na satisfação do consumidor entre países, porém com um conjunto alternativo de indicadores culturais, proposto previamente por Inglehart e Baker (2000). Os autores classificam as culturas como sendo sociedades de valores tradicionais e sociedades de valores seculares-racionais. A primeira classificação (sociedades de valores tradicionais) é caracterizada por altos níveis de orgulho nacional, favorável respeito à autoridade, atitudes protecionistas com relação ao comércio exterior e, entre outras características, preferência pela conformidade social do que a luta individualista, favorecimento ao consenso. Já as sociedades de valores seculares-racionais apresentam traços contrários em todos os aspectos mencionados.

Tais classificações se assemelham ao conceito de individualismo e coletivismo proposto por Hofstede et al. (2010). Membros de culturas coletivistas são mais propensos a abrir mão da sua opinião para prezar pela harmonia do grupo, já em culturas individualistas essa atitude é menos provável. Além disso, ao contrário das sociedades coletivistas, as individualistas consideram desejável haver competição entre membros, por mais que tal comportamento prejudique outras pessoas envolvidas (Yoo, 2009). Logo, percebe-se a relação entre coletivismo e valores tradicionais e individualismo e valores seculares-racionais.

Morgeson et al. (2011) concluíram que culturas que tendem para os valores seculares-racionais geralmente tem experiências e reportam menor satisfação como consumidores. Além disso, consumidores nas sociedades tradicionais tendem a experimentar e expressar níveis de satisfação bem mais elevados do que as sociedades seculares-racionais. Esses resultados sugerem que os fatores culturais devem ser contabilizados na comparação de resultados de satisfação entre as nações. Os achados sugerem, também, que os consumidores de alguns grupos culturais podem simplesmente serem mais difíceis de agradar (ou pelo menos, menos propensos a expressar prazer) do que outros. Tem-se, assim, a primeira hipótese do estudo:

H1: Membros de sociedades coletivistas expressam mais satisfação como consumidores em comparação a membros de sociedades individualistas.

Uma das características que Hofstede et al. (2010) atribuem ao individualismo é a confiança. Assim, sociedades individualistas são mais propensas a confiar em outras pessoas até que estas deem algum motivo para não confiar. Por outro lado, membros de culturas coletivistas apenas passam a confiar quando encontram motivos para fazê-lo. Aplicando esse conceito ao consumo, Jin, Park e Kim (2008) estudaram as possíveis diferenças entre Estados Unidos e Coréia do Sul no contexto de e-commerce e, ao contrário do que diz a teoria, ao comparar os resultados dos dois grupos culturais, não foram encontradas diferenças significantes na confiança, como forma a aumentar a lealdade. Jin et al. (2008) atribuem duas possíveis explicações para tais resultados: a escala usada ter sido muito simples, de forma que apenas mediu confiança sob a visão de credibilidade após a experiência de compra; e as várias experiências que os consumidores podem ter tido com os vendedores pesquisados.

No entanto, Park, Gunn e Han (2012) buscaram, também nos Estados Unidos e Coréia do Sul, diferenças culturais sob uma visão multidimensional da confiança. O construto foi medido através de três dimensões: competência, benevolência e integridade. Diferente do estudo citado anteriormente foi encontrada diferenças significantes, de forma que os norte-americanos (individualistas) apresentaram maior propensão a confiar em 
vendedores online em comparação aos sul-coreanos (coletivistas). Com vistas a analisar tais resultados, temse a segunda hipótese do presente estudo:

H2: Membros de sociedades individualistas tendem a confiar mais em uma marca do que membros de culturas coletivistas.

Sobre lealdade, Schau et al. (2009) declaram que, para construir um relacionamento de longa duração com os clientes, é necessário enaltecer e sustentar as relações entre os membros consumidores e a marca. Análogo a isso, Hofstede et al.(2010) afirmam que indivíduos membros de culturas individualistas possuem laços mais superficiais com os outros indivíduos fora do seu núcleo familiar. Por outro lado, integrantes de sociedades coletivistas são integradas forte e coesamente no grupo em que estão inseridos. Assim, consumidores coletivistas são mais leais a uma marca do que consumidores individualistas (Yoo, 2009), quando analisados em uma categoria específica de produto. Logo, tem-se a terceira hipótese do estudo:

H3: Membros de culturas coletivistas são mais propensos a serem leais do que membro de culturas individualistas.

Nesse sentido, Yoo (2009) afirma que indivíduos de sociedades coletivistas tendem a se importar mais com a opinião dos outros, não costumam tomar decisões sem ouvir a terceiros além de ser mais influenciáveis a ideias do seu grupo. Por outro lado, pessoas de culturas individualistas tendem a cuidar de si e prezar pelos seus próprios valores e opiniões (Hofstede et al., 2010).

Os consumidores de países mais coletivistas tendem a ter maior intenção de praticar de forma positiva o marketing boca a boca na condição de terem uma boa experiência. De forma contrária, indivíduos de culturas individualistas tendem a praticar apenas o marketing boca a boca na ocasião de uma experiência negativa, de forma a verbalizar a sua insatisfação (Furrer, Liu \& Sudharshan, 2001). Assim, no que diz respeito a uma das principais consequências de um consumidor leal, o marketing boca a boca, tem-se a seguinte hipótese:

H4: Membros de culturas coletivistas praticam mais marketing boca a boca do que membros de culturas individualistas.

Além disso, integrantes de sociedades individualistas não se importarão em trocar de marca se o objetivo for buscar maior satisfação (Yoo, 2009). Por outro lado, em culturas coletivistas, as pessoas, além de se preocuparem com o bem do grupo, continuam a fazê-lo ao longo do tempo em troca de lealdade mútua (Dick \& Basu, 1994). Com base nessas afirmações e sabendo que consumidores leais têm menos motivação a buscar novas opções e são menos influenciáveis a estratégias de marketing da concorrência (Kotler \& Keller ,2012), tem-se a quinta hipótese do estudo:

H5: Membros de culturas individualistas são mais vulneráveis, ou seja, menos resistentes, a esforços da concorrência do que membros de culturas coletivistas. 


\section{Método}

A fim de testar as hipóteses propostas foi aplicada uma pesquisa quantitativa de caráter descritivo e a operacionalização da pesquisa deu-se por experimento. A escolha da população alvo da pesquisa foi com base na classificação de países proposta por Hofstede et al. (2010), sobre a dimensão cultural individualismo (vs. coletivismo). A partir do ranking de países, escolheu-se aplicar a pesquisa nos Estados Unidos e Brasil. No que se refere aos sujeitos participantes, a seleção deu-se por conveniência.

$\mathrm{O}$ instrumento de coleta teve como objetivo obter dados quantitativos referentes à propensão de lealdade dos indivíduos, satisfação, confiança, e também, às consequências deste comportamento, no caso deste estudo, marketing boca a boca e resistência aos esforços da concorrência. A forma de coleta deu-se de forma estruturada, através de um questionário com perguntas fechadas avaliadas por meio de uma escala do tipo Likert de cinco pontos e questões de múltipla escolha.

Inicialmente, foram elaboradas questões de perfil como gênero, idade e renda para caracterizar a amostra dentro das nacionalidades estudadas. Para formulação das faixas de renda foi utilizada a classificação de classes sociais estipulada pelo IBGE, com base no salário mínimo brasileiro de 2017 e para adaptação dos valores entre os grupos culturais foi utilizado o Índice Big Mac (Economist, 2017). Posteriormente, foram abordadas as questões relativas ao tema e objetivos deste estudo baseadas em escalas previamente validadas em outros estudos e também de perguntas complementares. A fim de evitar desvios na pesquisa, foi elaborado um texto descrevendo uma situação hipotética, dentro do contexto de companhias aéreas, a fim de direcionar o pensamento dos respondentes acerca do mesmo objeto/serviço em análise. Foi escolhido esse serviço por ser de amplo conhecimento, e possivelmente de uso, dos dois grupos culturais parte da pesquisa.

A escala de Bennet e Rundle-Thiele (2002) foi utilizada para avaliar propensão de o indivíduo ser leal. Para medir confiança, foi utilizada a escala proposta por Park et al. (2012), esta que segrega o construto em três características para se obter uma avaliação mais completa sobre confiança. Sobre satisfação foi escolhida a escala de Voss, Parasuraman e Grewal (1998). Para mensurar a prática do marketing boca a boca, foram empregadas questões baseadas na escala de Price e Arnould (1999). Sobre a resistência à persuasão em relação à concorrência foi adaptada a escala proposta por Rundle-Thiele (2005).

Os respondentes dos dois países receberam o mesmo questionário apenas com variação de idioma: português e inglês. Os questionários passaram pelo processo de tradução reversa para português, uma vez que as escalas que compõem o instrumento são originalmente escritas na língua inglesa.

A coleta de dados para a amostra da pesquisa foi realizada pela internet, através de um link gerado na plataforma Qualtrics. Assim, para garantir o alcance de um número mínimo de 80 casos válidos por país foi utilizada a ferramenta de coleta Mechanical Turk, fornecida pela Amazon, para os respondentes dos Estados Unidos. No Brasil o link do questionário foi distribuído através de e-mail e mensagens nas redes sociais. Dessa forma, buscou-se um total mínimo de 160 casos válidos para análise. As respostas obtidas foram separadas em dois conjuntos, de forma a agrupar os respondentes das duas nacionalidades pesquisadas. Foram feitas análises de frequência e média. Na sequência, a fim de realizar testes de comparação de médias, foi utilizada a análise de variância (ANOVA).

\section{Análise e discussões dos resultados}

Foram obtidos 99 casos válidos norte-americanos (G1) e 86 brasileiros (G2). A média de idade do G1 é de 34,79 anos, enquanto a média do G2 é de 32,16 anos.Com relação ao gênero, o público feminino é 
predominante nos dois grupos (56\% em G1 e 67\% em G2). A faixa de renda que ficou em evidência entre os respondentes de G1 (36\%) foi a quarta faixa "Entre R\$ 9.371 (USD 2.901) e R\$ 18.740 (USD 5.627)", já $41 \%$ dos respondentes de G2 se encaixam na terceira faixa de renda "Entre R \$ 3.749 (USD 1.161) e R\$ 9.370 (USD 2.900)". Sobre o nível de escolaridade dos respondentes, $47 \%$ dos norte-americanos pesquisados possui ensino superior completo, enquanto $36 \%$ dos brasileiros possui ensino superior incompleto.

A análise de variância dos aspectos de perfil da amostra não indicou diferença significante entre os grupos. Dessa forma, uma vez que nenhuma questão de perfil apontou diferença significância entre brasileiros e norte-americanos, tem-se uma amostra homogênea para análise.

\subsection{Propensão a lealdade}

A maior média encontrada em ambos os grupos se refere à preferência dos respondentes em comprar pela internet marcas conhecidas por eles $(3,62$ e 4,34). Já a menor média, para o G1 $(2,64)$, trata-se do costume de comprar as mesmas marcas, mesmo que sejam marcas comuns. Para o G2, a média mais baixa também foi de 2,64, na afirmação que diz que a pessoa raramente indica novas marcas e produtos para os amigos. Considerando a média formada por todas as afirmações do construto, a média dos brasileiros $(3,35)$ é maior do que a média dos norte-americanos $(3,16)$.

A análise de variância indicou que há diferença significante entre os grupos pesquisados $(\mathrm{F}=4,255 ; \mathrm{p}=$ 0,040). Esse dado mostra que os respondentes brasileiros apresentam propensão à lealdade significantemente maior que os respondentes norte-americanos.

\section{Tabela 1.}

Médias de Propensão à lealdade

\begin{tabular}{l|c|c}
\multicolumn{1}{c|}{ Propensão à lealdade } & EUA & BRASIL \\
\cline { 2 - 3 } & Médias & Médias \\
\hline $\begin{array}{l}\text { Prefiro ficar com a marca que costumo comprar do que experimentar algo que não } \\
\text { tenho certeza }\end{array}$ & 3,51 & 3,50 \\
\hline $\begin{array}{l}\text { Se eu gosto de uma marca eu raramente a troco apenas para experimentar algo } \\
\text { diferente }\end{array}$ & 3,42 & 3,42 \\
\hline Eu raramente indico novas marcas e produtos para os meus amigos & 2,96 & 2,64 \\
\hline $\begin{array}{l}\text { Eu raramente arrisco comprar marcas desconhecidas, mesmo que isso signifique } \\
\text { menos variedade }\end{array}$ & 2,64 & 2,98 \\
\hline Costumo comprar as mesmas marcas, mesmo que sejam marcas comuns & 2,79 & 3,45 \\
\hline Prefiro esperar os outros testarem uma nova marca antes de eu experimentá-la & 3,62 & 3,12 \\
\hline Eu prefiro escolher marcas conhecidas quando compro pela internet & $\mathbf{3 , 1 6}$ & $\mathbf{3 , 3 5}$ \\
\hline
\end{tabular}

\subsection{Confiança}

A maior média encontrada no G1 foi de 4,07 na afirmação de que a companhia aérea foi hábil e capaz. Já a maior média para o G2 foi sobre a boa intenção da companhia, com 4,31. A menor média para o G1 foi quanto ao interesse da companhia aérea no bem-estar da família $(3,70)$ e para G2 a menor média $(3,43)$ relaciona-se à afirmação de que a companhia aérea cumpre as suas promessas. Mesmo essas sendo as menores médias, elas são maiores que 3, o que indica que, de certa forma, os grupos concordaram com as afirmações e expressam confiança diante do cenário apresentado. Considerando a média total de todas as afirmações pertencentes a este construto, os respondentes dos Estados Unidos obtiveram média maior $(3,93)$ que os brasileiros $(3,86)$. 
A ANOVA realizada mostrou que não há diferença significante entre $\mathrm{G} 1$ e $\mathrm{G} 2(\mathrm{~F}=0,445 ; \mathrm{p}=0,505)$. Isso mostra que, apesar de os americanos demonstrarem mais confiança com relação à companhia aérea frente à situação apresentada, a diferença entre os grupos não é estatisticamente significante (Tabela 2).

\section{Tabela 2.}

Médias de Confiança

\begin{tabular}{|c|c|c|c|}
\hline \multirow{2}{*}{ Dimensão } & \multirow{2}{*}{ Confiança } & EUA & BRASIL \\
\hline & & Médias & Médias \\
\hline \multirow{4}{*}{ Competência } & A companhia aérea foi competente e eficaz & 3,94 & 3,64 \\
\hline & A companhia aérea teve boa performance & 3,95 & 3,75 \\
\hline & De forma geral, a companhia aérea foi hábil e capaz & 4,07 & 3,87 \\
\hline & No geral, a companhia aérea mostrou experiência & 3,96 & 4,08 \\
\hline \multirow{3}{*}{ Benevolência } & A companhia aérea agiu com boa intenção & 3,87 & 4,31 \\
\hline & $\begin{array}{l}\text { Se João e a família precisassem de ajuda, a } \\
\text { companhia aérea faria o melhor para ajudá-los }\end{array}$ & 3,97 & 4,18 \\
\hline & $\begin{array}{l}\text { A companhia aérea ficou interessada no bem-estar da família e } \\
\text { não só no seu próprio }\end{array}$ & 3,70 & 3,58 \\
\hline \multirow{5}{*}{ Integridade } & A companhia aérea foi verdadeira com a família & 4,00 & 3,90 \\
\hline & Eu caracterizo a companhia aérea como honesta & 3,96 & 4,05 \\
\hline & $\begin{array}{l}\text { A companhia aérea cumpre com as suas } \\
\text { promessas }\end{array}$ & 3,85 & 3,43 \\
\hline & A companhia aérea foi sincera e genuína & 3,89 & 3,72 \\
\hline & TOTAL & 3,93 & 3,86 \\
\hline
\end{tabular}

\subsection{Satisfação}

A Tabela 3 mostra que os dois grupos culturais obtiveram suas menores médias sobre a mesma afirmação: "João ficou impressionado com os serviços da USC Airlines" (G1 = 3,11 e G2 = 2,39). A maior média de G1 $(3,55)$ encontra-se na afirmação que indica a satisfação de João e a maior média para G2 na afirmação que indica infelicidade de João com o serviço da USC Airlines. De forma geral, os norte-americanos se mostraram mais satisfeitos do que o grupo de brasileiros pesquisados, com médias de 3,36 e 3,15 respectivamente.

A análise de variância realizada indicou diferença significante entre os grupos $(F=4,687 ; p=0,032)$. Isso mostra que, de fato, os norte-americanos apresentaram uma maior satisfação com relação à companhia aérea frente à situação apresentada.

\section{Tabela 3.}

Médias de Satisfação

\begin{tabular}{l|c|c}
\multicolumn{1}{c|}{ Satisfação } & EUA & BRASIL \\
\cline { 2 - 4 } & \multicolumn{1}{c}{ Médias } & Médias \\
\hline João ficou satisfeito com os serviços da USC Airlines & 3,55 & 3,50 \\
\hline João ficou impressionado com os serviços da USC Airlines & 3,11 & 2,39 \\
\hline João ficou infeliz com os serviços da USC Airlines & 3,42 & 3,57 \\
\hline & TOTAL & $\mathbf{3 , 3 6}$ \\
\hline
\end{tabular}

\subsection{Consequências da lealdade}

Os resultados mostrados na Tabela 4 indicam que os respondentes norte-americanos praticariam mais marketing boca a boca $(3,45)$, com base na situação do questionário, do que os brasileiros $(3,26)$.A ANOVA 
indicou que não há diferença significante entre $\mathrm{G} 1$ e $\mathrm{G} 2(\mathrm{~F}=2,564 \mathrm{p}=0,111)$ quanto ao construto marketing boca a boca (Tabela 4$)$.

\section{Tabela 4.}

Médias de Marketing boca a boca

\begin{tabular}{l|c|c}
\multicolumn{1}{c|}{ Marketing boca a boca } & EUA & BRASIL \\
\cline { 2 - 3 } & Médias & Médias \\
\hline João recomendaria a USC Airlines para alguém que pedisse a sua opinião & 3,38 & 3,36 \\
\hline João diria coisas positivas sobre a USC Airlines para as outras pessoas & 3,53 & 3,19 \\
\hline João recomendaria a USC Airlines para as outras pessoas & 3,42 & 3,25 \\
\hline \multicolumn{1}{c}{ TOTAL } & $\mathbf{3 , 4 5}$ & $\mathbf{3 , 2 6}$ \\
\hline
\end{tabular}

Por fim, o último construto analisado (Tabela 5), foi o único de todos os fatores analisados que obteve médias gerais que indicam discordância com as afirmações (menor que 3). Os norte-americanos apresentaram maior média $(3,11)$ na afirmação de que optariam pela empresa citada mesmo que houvesse pequena diferença de preço. Já os brasileiros obtiveram seu maior valor médio $(2,89)$ sobre a afirmação de que escolheriam a empresa mesmo se vissem alguma avaliação negativa sobre a mesma.

A análise de variância realizada indicou diferença significante entre os grupos $(\mathrm{F}=15,687 \mathrm{p}=0,000)$. Apesar de as médias serem menores que 3, os norte-americanos, de fato, apresentam maior resistência à persuasão da concorrência.

\section{Tabela 5.}

Médias de Resistência à persuasão

\begin{tabular}{|c|c|c|}
\hline \multirow{2}{*}{ Resistência à persuasão } & EUA & BRASIL \\
\hline & Médias & Médias \\
\hline Se a USC Airlines aumentar o preço, João continuaria sendo consumidor da empresa & 2,90 & 2,51 \\
\hline $\begin{array}{l}\text { João compraria passagens da USC Airlines mesmo se visse alguma avaliação negativa } \\
\text { sobre a companhia }\end{array}$ & 2,94 & 2,89 \\
\hline João pagaria 5\% a mais para voar pela USC Airlines & 2,66 & 2,28 \\
\hline $\begin{array}{l}\text { João compraria voos com a USC Airlines mesmo que tenha uma pequena diferença de } \\
\text { preço }\end{array}$ & 3,11 & 2,65 \\
\hline João compraria passagens da USC Airlines independente do preço & 2,45 & 1,95 \\
\hline $\begin{array}{l}\text { João compraria passagens da USC Airlines mesmo se outra companhia oferecer } \\
\text { melhores serviços }\end{array}$ & 2,51 & 1,84 \\
\hline TOTAL & 2,76 & 2,36 \\
\hline
\end{tabular}

\section{Discussão dos resultados}

A partir das análises descritivas e paramétricas realizadas, cabe a discussão dos resultados encontrados, a sua relação com a teoria e a análise da confirmação, ou não, das hipóteses apresentadas. Sendo uma hipótese para cada um dos cinco construtos medidos, a Tabela 6 apresenta as hipóteses formuladas para este estudo.

\section{Tabela 6.}

Hipóteses

\begin{tabular}{|c|l|c|}
\hline HIPÓTESE & \multicolumn{1}{|c|}{ DESCRIÇÃO } & SITUAÇÃO \\
\hline H1 & $\begin{array}{l}\text { Membros de sociedades coletivistas expressam mais satisfação como consum- } \\
\text { idores em comparação a membros de sociedades individualistas. }\end{array}$ & Rejeitada \\
\hline
\end{tabular}




\begin{tabular}{|c|l|c|}
\hline H2 & $\begin{array}{l}\text { Membros de sociedades individualistas tendem a confiar mais em uma marca } \\
\text { do que membros de culturas coletivistas. }\end{array}$ & Rejeitada \\
\hline H3 & $\begin{array}{l}\text { Membros de culturas coletivistas são mais propensos a serem leais do que } \\
\text { membro de culturas individualistas. }\end{array}$ & Renfirmada \\
\hline H4 & $\begin{array}{l}\text { Membros de culturas coletivistas praticam mais marketing boca a boca do que } \\
\text { membros de culturas individualistas. }\end{array}$ \\
\hline H5 & $\begin{array}{l}\text { Membros de culturas individualistas são mais vulneráveis, ou seja, menos re- } \\
\text { sistentes, a esforços da concorrência do que membros de culturas coletivistas. }\end{array}$ & Rejeitada \\
\hline
\end{tabular}

Conforme as médias encontradas nos dois grupos e a análise de variância realizada para cada um dos construtos, encontrou-se a situação de que apenas a hipótese H3 foi confirmada, permitindo afirmar que os respondentes brasileiros são de fato mais propensos a serem leais que os respondentes norte-americanos. Assim, o resultado da pesquisa vai ao encontro do que diz Yoo (2009), quando afirma que consumidores coletivistas são mais leais a uma marca do que consumidores individualistas, quando analisados em uma categoria específica de produto. A escala que mediu a propensão a lealdade dos consumidores foi posicionada antes cenário experimental com o objetivo de medir sem qualquer viés de produto proporcionado pela pesquisa.

Retomando o que disse Ijewere e Odia (2012) o entendimento e o significado que a cultura dá ao produto e ao ato da compra influencia no processo de consumo. Furrer et al. (2000) complementam afirmando que desde que culturas variam com relação a respeito e normas de comportamento, consumidores de culturas diferentes provavelmente têm expectativas diferentes do que é um serviço ótimo ou adequado e consequentemente avaliam serviços de forma diferente. Uma vez que os passageiros aéreos interagem com o serviço antes, durante e às vezes após o voo, elementos culturais provavelmente surjam e tenham efeito significativo na formação de expectativas de serviço (Laroche, Kalamas \& Cleveland, 2004).

Dessa forma, o resultado da pesquisa colabora com Mellens et al. (1996). Os autores comentam que a lealdade atitudinal orientada pelo indivíduo considera a fidelidade a marcas como uma característica da personalidade do consumidor, independente da marca em questão. Logo, pode-se afirmar que, além de os membros de culturas coletivistas serem mais propensos à lealdade, sob a ótica de uma categoria de produto, o mesmo pode ser dito para a contexto geral de consumo.

Os antecedentes da lealdade, satisfação (H1) e confiança (H2), assim como as consequências da lealdade, marketing boca a boca (H4) e resistência do consumidor aos esforços do concorrente (H5) foram medidos após o texto com a situação hipotética que aborda o setor aéreo como situação de consumo. A hipótese 2 afirma que membros de culturas individualistas confiam mais em uma marca do que membros de culturas coletivistas. A média encontrada para os Estados Unidos $(3,93)$ é maior que a média brasileira $(3,86)$, porém estatisticamente não se mostra uma diferença significante. Esse resultado é contraditório ao achado de Park et al. (2012), que encontraram diferenças significantes com relação a confiança sob o segmento específico de e-commerce.

Por outro lado, as hipóteses 1, 4 e 5 foram rejeitadas pelo fato de as médias dos países não terem sido proporcionais para concordar com a teoria. Sobre satisfação $(\mathrm{H} 1)$ e marketing boca a boca $(\mathrm{H} 4)$, a teoria indica que o Brasil, sendo um país coletivista, obteria médias mais altas que as encontradas para os Estados Unidos, país individualista. Morgeson et al. (2011) falam sobre culturas tradicionais e de valores seculares-racionais, que de acordo com as definições de coletivismo e individualismo se relacionam respectivamente. Os autores afirmam que, após uma experiência, sociedades tradicionais (coletivistas) expressariam níveis de satisfação mais elevados que sociedades de valores seculares-racionais (individualistas). Os resultados indicaram uma 
inversão dessa afirmativa, uma vez que os norte-americanos apresentaram média maior de satisfação $(3,36)$ do que os brasileiros $(3,15)$, com diferença significante.

Quanto ao marketing boca a boca (H4), os resultados também contradizem a teoria. Segundo Liu et al. (2001), países coletivistas, representados pelo Brasil neste estudo, apresentariam média maior quando comparada à média dos países individualistas (Estados Unidos), porém o inverso ocorreu, conforme mostra a Tabela 8. Apesar de os norte-americanos terem apresentado média maior que os brasileiros $(3,45$ e 3,26) não há diferença significante, o que revela que os dois grupos são equivalentes. Os autores expõem as suas afirmações tendo como condição o consumidor ter passado pela experiência de consumo, da mesma forma como ocorreu com a satisfação, o texto pode não ter sido suficiente para obter a opinião real do respondente.

Por fim, os dois grupos pesquisados apresentaram médias inferiores a 3,0 (ponto neutro da escala) quando apresentadas afirmações que mediram sua resistência à persuasão. Sendo assim, pode-se dizer que no contexto estudado (companhias aéreas), tanto brasileiros quanto norte-americanos são vulneráveis e trocariam facilmente de marca. Porém, quando comparados, os norte-americanos obtiveram média mais alta $(2,76)$, estatisticamente significante, que os brasileiros $(2,36)$, o que mostra maior resistência à troca de companhia aérea. Esse resultado contraria a literatura que defende que consumidores leais são menos influenciáveis a estratégias de marketing da concorrência. Sob essa teoria, os brasileiros deveriam ter obtido maior média, já que países coletivistas são mais leais, como comprovado nesta pesquisa.

A fim de entender os resultados obtidos no presente trabalho, autores defendem que além das diferenças entre setores de consumo, a segmentação dentro do setor influencia na percepção e expectativas do consumidor (Laroche et al., 2004; Boetsch, Bieger \& Wittmer, 2011; Mikulic \& Prebezac, 2011). Nesse contexto, Boetsch et al. (2011) realizaram uma pesquisa com 682 passageiros, os quais $72 \%$ estavam esperando voos internacionais e iriam viajar na classe executiva (business class). Das cinco dimensões de valor ao consumidor medidas na pesquisa, contrariando pesquisas anteriores, o fator de maior relevância foi o valor emocional que a marca da companhia aérea possuía para o passageiro.

Ainda sobre marca, Matzler et al. (2008) defendem que ter uma marca sólida no mercado pode influenciar o consumidor a reduzir suas opções de escolha, em determinada decisão de compra, de forma a comprar um produto de uma marca que lhe ofereça menos riscos e lhe transmita confiança. Uma vez que a companhia aérea informada no texto é fictícia, a falta de background sobre a reputação da marca, logo, o não conhecimento da mesma pelos respondentes e a importância do valor emocional que a marca representa no setor aéreo, pode ter distorcido a percepção dos consumidores.

Além disso, Boetsch et al. (2011) afirmam que as preferências que são relevantes para a escolha de uma companhia aérea são baseadas em experiências pessoais e valores como a imagem e os atributos de confiança. Devido às diferentes referências de companhias aéreas é clara que as preferências e percepções são altamente dependentes de experiências passadas. Além disso, a cultura também influencia no processo de decisão de compra, pois os elementos do serviço possuem significados diferentes para cada segmento de consumidor. Logo, as experiências anteriores dos respondentes brasileiros e norte-americanos e a falta de experiência real da situação exposta no texto pode ter influenciado a avaliação dos elementos abordados.

Sobre os elementos que compõem o serviço de uma companhia aérea, há diferenças de importância para pessoas que costumam voar com companhias tradicionais e para pessoas que voam com companhias de baixo custo. Uma dessas diferenças é com relação à experiência de voo, mais especificamente às refeições, que impacta fortemente a experiência de passageiros de companhias tradicionais e não à de companhias de baixo 
custo. Além disso, clientes de companhias de baixo custo estão mais preocupados com a segurança do voo do que a pontualidade, enquanto acontece o inverso com os passageiros de companhias tradicionais (Mikulic \& Prebezac, 2011).

Outro segmento dentro do setor de voos comerciais são as diferenças de cabines (primeira classe, classe executiva e classe econômica). Pessoas que costumam viajar na primeira classe são consideravelmente menos sensíveis a preço e possuem maior afinidade com a questão de marca e dão mais importância ao conforto do que pessoas que viajam na classe executiva e econômica (Boetsch et al., 2011). Dessa forma, pode ter havido, com base na realidade da aviação de cada país e as experiências passadas dos respondentes, um viés com relação ao tipo de companhia aérea que a USC Airlines pode ser (tradicional ou de baixo custo) e em qual cabine a família estava acomodada.

\section{Conclusões}

O presente estudo teve como objetivo geral analisar a propensão à lealdade, seus antecedentes e consequências em dois grupos culturais distintos: Brasil e Estados Unidos.Como primeira conclusão, os resultados confirmaram a teoria de Yoo (2009) de que consumidores coletivistas têm maior propensão à lealdade do que consumidores individualistas. Já a os demais construtos foram avaliados com base em um cenário experimental. Neste caso, os resultados de satisfação, marketing boca a boca e resistência à persuasão, foram diferentes do indicado pela teoria.

Hofstede et al. (2010) afirmam que sociedades individualistas são mais propensas a confiar até que haja razões para não confiar. Por outro lado, membros de culturas coletivistas apenas passam a confiar quando encontram motivos para fazê-lo. Os resultados da pesquisa corroboram essa afirmação, ainda que a diferença entre os grupos não tenha sido significante. Da mesma forma como no estudo de Jin et al. (2008) no contexto de e-commerce, em que também não foram encontradas diferenças significantes com relação a confiança. Esse resultado, assim como o dos referidos autores, pode-se atribuir às várias experiências que os consumidores podem ter tido com companhias aéreas dos seus países.

Já com relação aos outros construtos, os respondentes dos dois grupos culturais se mostraram satisfeitos com a companhia aérea citada no experimento, assim como mostraram-se predispostos a realizar marketing boca a boca, uma vez que as suas médias foram maiores que 3,0 (ponto neutro da escala). Porém, os norteamericanos apresentaram médias significantemente maiores que as dos brasileiros. Sobre à resistência dos pesquisados à persuasão, este foi o único construto que os dois grupos apresentaram médias menores que 3,0, indicando que ambos seriam vulneráveis a trocar de marca no contexto apresentado.

Por fim,o setor de consumo abordado no experimento, voos comerciais, segundo Boetsch et al. (2011), Mikulic e Prebezac (2011) e Laroche et al. (2004), possui algumas características capazes influenciar a avaliação do serviço e da marca por parte do consumidor. Dentre elas, três podem ter sido chave para acarretar nos resultados obtidos: a marca, a segmentação do setor e a importância das experiências anteriores.

Dessa forma, os respondentes de Estados Unidos e Brasil podem ter interpretado a situação fictícia citada no experimento de forma diferente conforme a realidade e peculiaridades em cada país. Isto é, os respondentes de um país podem ter considerado a USC Airlines uma companhia aérea de baixo custo, enquanto os respondentes do outro país podem ter a considerado como uma empresa tradicional. Além disso, pode ter havido diferenças na interpretação no caso de a família citada no experimento ser cliente de primeira classe ou classe econômica, o que pode ter influenciado nas expectativas e avaliação do serviço. 
Os resultados obtidos nesse estudo representam uma ferramenta de análise para as estratégias de marketing das companhias aéreas que operam nos Estados Unidos e no Brasil. Dessa forma, os profissionais de marketing devem olhar para as análises realizadas, compará-las com as atuais estratégias e adaptá-las visando melhores resultados. Com relação a satisfação, sugere-se que as empresas realizem estudos que identifiquem os atributos mais importantes para os brasileiros, nesse setor de consumo, para que o serviço no Brasil seja adaptado e atinja melhores níveis de satisfação.

Apesar de as médias de predisposição à realização de marketing boca a boca terem sido positivas nos dois grupos culturais, os brasileiros se mostraram menos propensos para tal do que os norte-americanos. As empresas devem promover ações que incentivem a indicação dos serviços para terceiros. Uma ideia inicial é a criação de campanhas promocionais que estimulem os consumidores a praticar o marketing boca a boca. $\mathrm{O}$ único construto em que os dois grupos culturais obtiveram médias abaixo de 3,0 (ponto neutro da escala) foi o que aborda a resistência do consumidor à persuasão do concorrente. Logo, brasileiros e norte-americanos se mostraram vulneráveis a troca de marca. Esse resultado indica para as empresas que operam no Brasil e nos Estados Unidos que deve haver maior investimento em programas de fidelidade e outras ações que torne o consumidor mais resistente a trocar de companhia aérea.

Sobre o desenvolvimento deste trabalho, algumas limitações devem ser consideradas. A escolha de um contexto específico para o cenário experimental representa uma grande limitação, que impacta nas implicações gerencias, por serem direcionadas, neste caso, para as empresas áreas. Além disso, a quantidade de países que fizeram parte do estudo restringe a análise às suas características culturais, assim como a dimensão utilizada, individualismo.

Este estudo representa um ponto de partida para pesquisas futuras discutirem a particularidade da avaliação dos elementos de serviço dentro da indústria aérea. Sugere-se medir satisfação, confiança, marketing boca a boca e resistência aos esforços do concorrente sob as dimensões de serviço do segmento de voos comerciais, entre Estados Unidos e Brasil, para confirmar os achados deste trabalho. Além disso, com base nos resultados encontrados, sugere-se a análise dos construtos dentro de cada país analisado, de forma a verificar a relação dos construtos no grupo de norte-americanos e no grupo de brasileiros, separadamente. Assim, pode-se traçar um perfil referente à lealdade no contexto de serviços aéreos.

\section{Referências}

Albert, N., Merunka, D., \& Valette-Florence, P. (2013). Brand passion: Antecedents and consequences. Journal of Business Research, 66(7), 904-909. Retrieved from $<\mathrm{http}$ ://www.lalondeconference.com/CB/2011_ lalonde_seminar/papers/Paper_182_ALBERT_Valette_Florence_Pierre.pdf $>$

Bennett, R., \& Rundle-Thiele, S. (2002). A comparison of attitudinal loyalty measurement approaches. Journal of Brand Management, 9(3), 193-209. Retrieved from <http://eprints.qut.edu.au/13257/1/13257a.pdf>

Bloemer, J. M., \& Kasper, H. D. (1995). The complex relationship between consumer satisfaction and brand loyalty. Journal of economic psychology, 16(2), 311-329. Retrieved from <http:/www.sciencedirect.com/ science/article/pii/016748709500007B> 
Boetsch, T., Bieger, T., \& Wittmer, A. (2011). A customer-value framework for analyzing airline services. Transportation Journal, 50(3), 251-270.

Caruana, A. (2003). The impact of switching costs on customer loyalty: A study among corporate customers of mobile telephony. Journal of Targeting, Measurement and Analysis for marketing, 12(3), 256-268.

Delgado-Ballester, E., \& Luis Munuera-Alemán, J. (2001). Brand trust in the context of consumer loyalty. European Journal of marketing, 35(11/12), 1238-1258. Retrieved from < https://www.emeraldinsight.com/ doi/abs/10.1108/EUM0000000006475>

Dick, A. S., \& Basu, K. (1994). Customer loyalty: toward an integrated conceptual framework. Journal of the academy of marketing science, 22(2), 99-113. Retrieved from < https://journals.sagepub.com/doi/ abs/10.1177/0092070394222001>

Evanschitzky, H., Ramaseshan, B., Woisetschläger, D. M., Richelsen, V., Blut, M., \& Backhaus, C. (2012). Consequences of customer loyalty to the loyalty program and to the company. Journal of the Academy of Marketing Science,40(5), 625-638. Retrieved from <https://link.springer.com/article/10.1007/s11747-0110272-3>

Frank, B., Enkawa, T., \& Schvaneveldt, S. J. (2015). The role of individualism vs. collectivism in the formation of repurchase intent: A cross-industry comparison of the effects of cultural and personal values. Journal of Economic Psychology, 51, 261-278. Retrieved from <http://www.sciencedirect.com/science/article/pii/ S0167487015001063>

Furrer, O., Liu, B. S. C., \& Sudharshan, D. (2000). The relationships between culture and service quality perceptions: Basis for cross-cultural market segmentation and resource allocation. Journal of service research, 2(4), 355-371. Retrieved from <http://journals.sagepub.com/doi/abs/10.1177/109467050024004>

Liu, B. S. C., Furrer, O., \& Sudharshan, D. (2001). The relationships between culture and behavioral intentions toward services. Journal of service research, 4(2), 118-129. Retrieved from $<$ http://journals.sagepub.com/doi/ pdf/10.1177/109467050142004>

Han, S. P., \& Shavitt, S. (1994). Persuasion and culture: Advertising appeals in individualistic and collectivistic societies. Journal of experimental social psychology, 30(4), 326-350. Retrieved from $<\mathrm{http}: / / \mathrm{www}$.sciencedirect. com/science/article/pii/S002210318471016X>

Hofstede, G. (1983). The cultural relativity of organizational practices and theories. Journal of international business studies, 14(2), 75-89. Retrieved from <http://www.aogaku-daku.org/wp-content/uploads/2011/07/ culturalRelativity10.pdf>

Hofstede, G., Hofstede, G. J. \& Minkov, M. (2010). Cultures and Organizations: Software of the Mind (Rev. 3 rd ed.). New York: McGraw-Hill. 
Hur, W. M., Kang, S., \& Kim, M. (2015). The moderating role of Hofstede's cultural dimensions in the customer-brand relationship in China and India. Cross Cultural Management, 22(3), 487-508. Retrieved from $<$ http://www.emeraldinsight.com/doi/abs/10.1108/CCM-10-2013-0150>

Ijewere, A. A., \& Odia, E. O. (2012). Cultural influences on product choice of the Nigerian consumer. Indian Journal of Economics and Business, 11(1). Retrieved from <http://search.proquest.com/openview/ a966f530429c18f274a205dabb43bdb9/1.pdf?pq-origsite=gscholar\&cbl=2026690>

Inglehart, R., \& Baker, W. E. (2000). Modernization, cultural change, and the persistence of traditional values. American sociological review, 19-51. Retrieved from $<$ http://my.fit.edu/ gabrenya/cultural/readings/ Inglehart-Baker-2000.pdf>

Inglehart, R., \& Baker, W. E. (2000). Modernization, cultural change, and the persistence of traditional values. American sociological review, 19-51. Retrieved from $<$ http://my.fit.edu/ gabrenya/cultural/readings/ Inglehart-Baker-2000.pdf>

Jin, B., Yong Park, J., \& Kim, J. (2008). Cross-cultural examination of the relationships among firm reputation, e-satisfaction, e-trust, and e-loyalty. International Marketing Review, 25(3), 324-337.

KOTLER, P., \& KELLER, K. L. (2012). Administração de Marketing. Tradução de Sônia Midori Yamamoto.

Kuenzel, S., \& Vaux Halliday, S. (2008). Investigating antecedents and consequences of brand identification. Journal of Product \& Brand Management, 17(5), 293-304. Retrieved from < http://www.emeraldinsight.com/ doi/abs/10.1108/10610420810896059>

Laroche, M., Kalamas, M., \& Cleveland, M. (2005). "I" versus “we" how individualists and collectivists use information sources to formulate their service expectations. International marketing review, 22(3), 279-308. Retrieved from < http:/www.emeraldinsight.com/doi/abs/10.1108/02651330510602213>

Li, X. (2010). Loyalty regardless of brands? Examining three nonperformance effects on brand loyalty in a tourism context. Journal of Travel Research, 49(3), 323-336. Retrieved from <http://journals.sagepub.com/ doi/pdf/10.1177/0047287509346854>

Matzler, K., Grabner-Kräuter, S., \& Bidmon, S. (2008). Risk aversion and brand loyalty: the mediating role of brand trust and brand affect. Journal of Product \& Brand Management, 17(3), 154-162. Retrieved from <http:// www.emeraldinsight.com/doi/abs/10.1108/10610420810875070>

Mellens, M., Dekimpe, M., \& Steenkamp, J. B. E. M. (1996). A review of brand-loyalty measures in marketing. Tijdschrift voor economie en management, (4), 507-533. Retrieved from $<$ https://lirias.kuleuven. 
be/bitstream/123456789/119352/1/tem1996-4_507533p.pdf>

Mikulić, J., \& Prebežac, D. (2011). What drives passenger loyalty to traditional and low-cost airlines? A formative partial least squares approach. Journal of Air Transport Management,17(4), 237-240. Retrieved from <http://www.sciencedirect.com/science/article/pii/S0969699710000864>

Morgeson, F. V., Mithas, S., Keiningham, T. L., \& Aksoy, L. (2011). An investigation of the cross-national determinants of customer satisfaction. Journal of the Academy of Marketing Science,39(2), 198-215.

Park, J., Gunn, F., \& Han, S. L. (2012). Multidimensional trust building in e-retailing: Cross-cultural differences in trust formation and implications for perceived risk. Journal of Retailing and Consumer Services, 19(3), 304312.

Price, L. L., \& Arnould, E. J. (1999). Commercial friendships: Service provider-client relationships in context. Journal of marketing, 63(4), 38-56.

Rundle-Thiele, S. (2005). Exploring loyal qualities: assessing survey-based loyalty measures. Journal of Services Marketing, 19(7), 492-500. Retrieved from <http:/www.emeraldinsight.com/doi/ abs/10.1108/08876040510625990

Schau, H. J., Muñiz Jr, A. M., \& Arnould, E. J. (2009). How brand community practices create value. Journal of marketing, 73(5), 30-51. Retrieved from <http://citeseerx.ist.psu.edu/viewdoc/ download?doi=10.1.1.467.1331\&rep=rep1\&type=pdf $>$

Solomon, M. R. (2016). O Comportamento do consumidor-: comprando, possuindo e sendo. Bookman Editora.

The Economist. The Big Mac Index (2017). Retrieved from <http://www.economist.com/content/big-macindex $>$

Thompson, F. M., Newman, A., \& Liu, M. (2014). The moderating effect of individual level collectivist values on brand loyalty. Journal of Business Research, 67(11), 2437-2446. Retrieved from <http://isiarticles.com/ bundles/Article/pre/pdf/44937.pdfs

Triantafillidou, A., \& Siomkos, G. (2014). Consumption experience outcomes: satisfaction, nostalgia intensity, word-of-mouth communication and behavioural intentions. Journal of Consumer Marketing, 31(6/7), 526540. Retrieved from <http://www.emeraldinsight.com/doi/abs/10.1108/JCM-05-2014-0982>

Voss, G. B., Parasuraman, A., \& Grewal, D. (1998). The roles of price, performance, and expectations in determining satisfaction in service exchanges. Journal of marketing, 62(4), 46-61.

Yoo, B. (2009). Cross-national invariance of the effect of personal collectivistic orientation on brand loyalty 
and equity: The United States versus South Korean consumers. Asia Pacific Journal of Marketing and Logistics, 21(1), 41-57. Retrieved from <http://www.emeraldinsight.com/doi/abs/10.1108/13555850910926236> Warlop, L., Ratneshwar, S., \& Van Osselaer, S. M. (2005). Distinctive brand cues and memory for product consumption experiences. International Journal of Research in Marketing, 22(1), 27-44. Retrieved from $<$ http://www.sciencedirect.com/science/article/pii/S0167811604000618> 